\title{
Comparative Study on Cerebral Processing among Elderly People with Either Intellectual or Mechanical Work Activities, by Means of Electroencephalographic Techniques
}

\author{
Arisson Euclides da Silva1 (1), Leonardo Coelho de Mendonça Silva1 (i), \\ Lousane Leonoura Alves Santos ${ }^{1}{ }^{(0)}$, Diêgo Lucas Ramos e Silva1 ${ }^{\circledR}$, Milton Vieira Costa1 (i), \\ Paulo José Medeiros de Souza Costa ${ }^{2}$ (D), José Claudio da Silva1 ${ }^{1}$, \\ Euclides Mauricio Trindade Filho ${ }^{*}$ (i)
}

${ }^{1}$ State University of Health Sciences of Alagoas, Biological Science Nucleus, Maceió, Brasil

${ }^{2}$ State University of Health Sciences of Alagoas, Nucleus of Maternal Child and Adolescent Health, Maceió, Brasil

Email: *emtfilho@gmail.com

How to cite this paper: da Silva, A.E., de Mendonça Silva, L.C., Santos, L.L.A., e Silva, D.L.R., Costa, M.V., de Souza Costa, P.J.M., da Silva, J.C. and Filho, E.M.T. (2020) Comparative Study on Cerebral Processing among Elderly People with Either Intellectual or Mechanical Work Activities, by Means of Electroencephalographic Techniques. Journal of Behavioral and Brain Science, 10, 311-322. https://doi.org/10.4236/jbbs.2020.108020

Received: June 24, 2020

Accepted: August 8, 2020

Published: August 11, 2020

Copyright $\odot 2020$ by author(s) and Scientific Research Publishing Inc. This work is licensed under the Creative Commons Attribution International License (CC BY 4.0).

http://creativecommons.org/licenses/by/4.0/ (c) (i) Open Access

\begin{abstract}
Background: The cognitive capacity is one of the determinants of quality of life in old age. In EEG, gamma rhythm represented electrical correlates of execution of cognitive activities. Objective: To compare the cortical areas activated during executive activities through the gamma rhythm $(25-45 \mathrm{~Hz})$ and the performance in the Frontal Assessment Battery (FAB) among older people who exercised intellectual and mechanical work during their lifetime. Methods. We compared the electroencephalographic record of the gamma rhythm potential $(25-45 \mathrm{~Hz})$ in the cortical quadrants during the execution of the FAB among 13 elderly people who exercised intellectual activity and 12 elderly people who performed mechanical work. Results. In the FAB, the intellectual group obtained a better performance with a mean score of $16.2 / 18$, while the mechanical group obtained an average score of 14.9/18. Only a significant difference between groups was observed in the similarity test, with intellectual group leadership. There was no significant difference between groups in the overall analysis of gamma rhythm potential in the brain quadrants during the tests. Conclusion: Elderly people who performed intellectual activity performed better than the elderly who exercised mechanical work in the execution of the Frontal Evaluation Battery (FAB). There was a greater quantification of gamma rhythm in the group of elderly individuals who exercised intellectual activity, compared to those who exercised mechanical activity.
\end{abstract}




\section{Keywords}

Electroencephalography, Aged, Gamma Rhythm

\section{Introduction}

Work activity can be mechanical or cognitive. Mechanical work activity involves greater physical effort: for example, farm workers who manually cut sugar cane need to exert great physical effort. Intellectual work activity involves specialized knowledge, i.e. the use of abilities such as calculation, problem-solving or administration, among other activities that demonstrate complex reasoning. Doctors who study and practice what they have learned provide an example of this [1].

Cognition pays a central role in the aging process and presents an important association with quality of life [2]. Aging gives rise to change in cognitive patterns among elderly people, especially in relation to executive functions. There is a need for interventions aimed at minimizing the losses caused through the aging process [3]. The way in which this deterioration occurs and the impact that it has is not the same for all elderly people, and this deterioration does not follow any set pattern [4]. Nonetheless, studies have shown that such losses can be compensated for, and that cognitive training has the capacity to maintain and improve cognitive abilities among healthy elderly people and, consequently, their perception of quality of life [3] [5].

Since cognitive capacity is one of the determinants of quality of life in old age, cognitive decline indicates that there is a need to seek preventive measures for cognitive rehabilitation, with the aim of ensuring this quality of life [6]. Executive function is a general term that portrays distinct cognitive processes relating to control over attention, regulation of behavior and conduct directed by objectives. It is strongly related to the prefrontal cortex [7].

The Frontal Assessment Battery (FAB) was put forward as a brief diagnostic tool for use in cases of executive dysfunction syndrome. It consists of six subtests: similarities test (FAB1), lexical fluency test (FAB2), motor sequences test (FAB3), conflicting instructions test (FAB4), go-don't go test (FAB5) and prehension behavior test (FAB6). Each of these has the aim of exploring the functions relating to cognitive activity [8].

Electroencephalograms record mixtures of rhythmic voltage fluctuations that resemble sine waves. These represent variations in voltage differences between pairs of points on the surface of the cranium [9]. Recently, Filho et al. 2016 [10] suggested that frequencies between 25 and $45 \mathrm{~Hz}$, which they named gamma rhythm, represented electrical correlates of execution of cognitive activities. Thus, recording gamma rhythms in a given cortical area during execution of a mental activity would suggest that this area was responsible for processing this mental activity. 
It is likely that plastic alterations that have occurred in the brains of elderly individuals over the course of many years of eminently manual or eminently intellectual work can result in differences in cerebral processing. Therefore, the aim of the present study was to compare frontal cortical activity and performance during activities involving executive function, with measurement using the FAB.

\section{Method}

This was an observational cross-sectional study on a convenience sample of 25 elderly people. The research participants were recruited through an active search among the elderly who were enrolled in an open university program for the third age (UNCISATI) within the Health Sciences University of Alagoas (UNCISAL). They comprised 13 individuals whose working lives had solely involved intellectual activities and 12 with solely mechanical activities. This research project was approved by the UNCISAL ethics committee under report no. 1, 915, 298.

Volunteers to participate in this study recruited after approval had been granted, through an active search in UNCISATI, under documented authorization from the project coordinator. Data-gathering was performed between July and December 2018. Individuals of either sex who were 60 years of age or over were selected. These individuals' name, age, former work occupation, contact telephone number and city district of residence were noted. They were divided into two groups according to the profession that they had worked within: an intellectual group and a mechanical group. The elderly people in the intellectual group had worked as teachers, school directors, company administrators and bank officials, among other professions; while those in the mechanical group had worked as craftsmen, domestic helpers, market stallholders and truck drivers, among other professions. The subjects' personal information was kept confidential. Individuals presenting the following situations were excluded from the sample: those with neurological or psychiatric conditions; those who were using psychotropic drugs; and those who refused to sign the free and informed consent statement.

The study was conducted in the neurosciences laboratory of UNCISAL, in the city of Maceió, Alagoas. The electroencephalographic recordings were made using a 20-channel machine with 12-bit processor and sampling frequency of 256 $\mathrm{Hz}$ (EMSA, model 2031). Placement of electrodes on the subject's scalp was done in accordance with the 10 - 20 international system, with 22 electrodes.

The nominal qualitative variable used was the work activity that had been performed for most of the subject's life, which was characterized as intellectual or mechanical. The secondary variables came from topographic analysis of cerebral frequencies, which were quantitatively measured through the potency of the gamma rhythms in each cerebral quadrant (right anterior quadrant, left anterior quadrant, right posterior quadrant and left posterior quadrant) and the subject's performance in terms of FAB score. 
The electroencephalographic recordings were made in the mornings, between 8:00 am and 12:00 noon. During each recording session, there was an initial 60-second period of baseline recording in which the subject was asked to remain quiet with his or her eyes closed. After this, the FAB was applied. This was done blindly by a professional who had been properly trained. The FAB consisted of six subtests interspersed with free resting periods with eyes closed for 60 seconds, as follows:

1) Similarities test (FAB1) for 15 seconds: three pairs of images that had similarities to each other were presented, and the individual was asked to identify the similarity. Three correct responses was scored as three points; two correct responses as two points; one correct response as one point; and no correct response as zero points.

2) Lexical fluency test (FAB2) for 60 seconds: the individual was asked to say as many words as possible beginning with the letter $S$, except for proper names and derived words. More than nine correct words was scored as three points; six to nine words as two points; three to five words as one point; and less than three words as zero points.

3) Motor sequence test (FAB3) for 60 seconds: the individual was asked to perform a motor sequence consisting of tapping consecutive groups of fist-palm-fist against his or her thigh. Achievement of at least six consecutive motor sequences (fist-palm-fist) was scored as three points; achievement of three to five consecutive sequences (fist-palm-fist) was scored as two points; if the individual failed in the task alone but was able to perform three consecutive sequences (fist-palm-fist) with aid from the examiner, this was scored as one point; and if the individuals performed between zero and three consecutive sequences (fist-palm-fist), this was scored as zero points.

4) Conflicting instructions test (FAB4) for 60 seconds: the individual was asked to clap his or her hands once when the examiner clapped twice and and twice when the examiner clapped once. No mistakes was scored as three points; one or two mistakes as two points; three mistakes as one point; and four or more mistakes as zero points.

5) Go-don't go test (FAB5) for 60 seconds: the individual was asked to clap his or her hands once when the examiner clapped once and not clap when the examiner clapped twice. No mistakes was scored as three points; one or two mistakes as two points; three mistakes as one point; and four or more mistakes as zero points.

6) Prehension behavior test (FAB6): the individual, with eyes closed, was asked to place his or her left hand, with the palm facing up, on his or her knees. Then, without any warning or any instruction, the examiner place one finger on this individual's upturned palm. If the individual did not grip the examiner's finger, or hesitated or asked what to do, this was scored as three points; hesitating or asking what to do was scored as two points; gripping the examiner's finger without hesitation was scored as one point; and gripping the examiner's finger 
even after the examiner instructed the individual not to do so was scored as zero points.

For topographic analysis of the Electroencephalograms (EEGs), three two-second periods that were free of artefacts, both during the quiet period with eyes closed and during each subtest of the FAB, were selected. The traces thus obtained were analyzed via the Braintech XP software. In this, through use of Fourier transformations, five rhythm bands on the EEG were separated. In the present study, the band corresponding to the gamma rhythm $(25-45 \mathrm{~Hz})$ was used, according to the cortical quadrant. The quadrants analyzed were as follows: right anterior (RA), left anterior (LA), right posterior (RP) and left posterior (LP).

\section{Statistical Analysis}

Descriptive statistical tables were applied, including tables. The analysis was performed with the aid of the BioEstat 5.0 software. Student's $t$ test was applied to analyze the potency of the gamma rhythm in the four quadrantes, between the two groups. The chi-square test was used to compare the execution of the different FAB subtests between the two groups. The significance level was taken to be 0.05 .

\section{Results}

In the group of elderly people with intellectual work activities, the mean age was 69 years, with a range from 63 to 86 years. Among those with mechanical activities, the mean was 63.8 years, ranging from 60 to 79 years. Regarding the number of years of schooling, the intellectual group had had a mean of 15.4 years, ranging from 8 to 18 years. On the other hand, the mean was 10.4 years in the mechanical group, ranging from 5 to 16 years. Analysis on the participants' current activities showed that they were almost all doing activities that required mechanical actions. This accounted for $100 \%$ of the mechanical group and $93 \%$ of the intellectual group. Thus, only $7 \%$ of the intellectual group was still performing some type of activity of an intellectual nature (Table 1).

The FAB was applied to 13 elderly people who had done intellectual work activities and to 12 who had done mechanical work activities. These tests were applied while EEG tracings were being obtained to ascertain the subjects' electrical activity during the tasks. In the intellectual group, the scores ranged from 15 to 18 , with a general mean of 16.2 points (Table 2 ). In the mechanical group, the scores ranged from 13 to 17 , with a general mean of 14.9 points. Thus, overall, the intellectual group presented better performance $(\mathrm{p}=0.02)$.

Regarding each activity in particular (Table 2), a significant difference ( $\mathrm{p}=$ 0.006 ) between the groups was only observed in the FAB1 activity, in which the intellectual group had a mean score of 2.30 points while the mechanical group scored 1.33. Empirically, it was observed during the experiment that this was the test that was the most difficult to do. 
Table 1. Elderly characteristics in the intellectual and mechanical group.

\begin{tabular}{|c|c|c|c|c|c|}
\hline General aspects & \multicolumn{2}{|c|}{ Intellectual } & \multicolumn{2}{|c|}{ Mechanical } & $\mathrm{P}$ \\
\hline Number of elderlies & \multicolumn{2}{|c|}{13} & \multicolumn{2}{|c|}{12} & \\
\hline Age (years, $\mathrm{A} \pm \mathrm{SD}$ ) & \multicolumn{2}{|c|}{$69 \pm 3$} & \multicolumn{2}{|c|}{$63.8 \pm 2$} & 0.04 \\
\hline Male gender & \multicolumn{2}{|c|}{1} & \multicolumn{2}{|c|}{2} & \\
\hline Female gender & \multicolumn{2}{|c|}{12} & \multicolumn{2}{|c|}{10} & \\
\hline Wage Income & \multicolumn{2}{|c|}{$4.5 \mathrm{MS}$} & \multicolumn{2}{|c|}{$3.8 \mathrm{MS}^{*}$} & \\
\hline Years of study & \multicolumn{2}{|c|}{$15.4 \pm 2$} & \multicolumn{2}{|c|}{10.42} & 0.02 \\
\hline Current activity & $\mathrm{N}^{\circ}$ & $\%$ & $\mathrm{~N}^{\circ}$ & $\%$ & \\
\hline Intellectual & 1 & 7 & 0 & 0 & 0.07 \\
\hline Mechanical & 12 & 93 & 12 & 100 & \\
\hline
\end{tabular}

* Monthly salary.

Table 2. Results of the Frontal Assessment Battery (FAB) among the elderly in the intellectual and mechanical group.

\begin{tabular}{cccc}
\hline Score & Intellectual & Mechanical & \multirow{2}{*}{$\mathrm{P}$} \\
\cline { 2 - 3 } FAB & $\mathrm{A} \pm \mathrm{SD}$ & $\mathrm{A} \pm \mathrm{SD}$ & \\
\hline GLOBAL & $16.23 \pm 1.16$ & $14.91 \pm 1.50$ & 0.02 \\
FAB 1 & $2.30 \pm 0.75$ & $1.33 \pm 0.88$ & 0.006 \\
FAB 2 & $2.76 \pm 0.43$ & $2.41 \pm 0.66$ & 0.22 \\
FAB 3 & $2.69 \pm 0.48$ & $2.91 \pm 0.28$ & 0.34 \\
FAB 4 & $2.84 \pm 0.37$ & $3.00 \pm 0$ & 0.51 \\
FAB 5 & $2.61 \pm 0.65$ & $2.41 \pm 0.79$ & 0.58 \\
FAB 6 & $3 \pm 0$ & $3 \pm 0$ & 1.00 \\
\hline
\end{tabular}

The analysis on the other activities did not show any great difference between the groups (Table 2). It was also observed empirically that the intellectual group tended to do the activities FAB2 and FAB5 better, while the mechanical group was more effective in the activities FAB3 and FAB4. One important result was that both groups scored $100 \%$ in the activity FAB6.

\section{Gamma Rhythm}

The analysis on the data obtained during the FAB activities in the two groups (Table 3) demonstrated that there was no significant difference in predominance of gamma rhythm among the cerebral quadrants. However, it should be noted that separately, the intellectual group had greater gamma rhythm in the activities FAB2, FAB5 and FAB6. On the other hand, the mechanical group presented greater uniformity of performance, but with a slightly higher level in the activities FAB4 and FAB5.

The overall analysis on cerebral area measurements (Table 4) showed that in the intellectual group, the gamma rhythm predominated slightly in the areas of the right cerebral hemisphere. On the other hand, in the mechanical group, this rhythm had greater influence in the left cerebral hemisphere. 
Table 3. Gamma rhythm by activity Frontal Assessment Battery (FAB) between the intellectual and mechanical groups.

\begin{tabular}{cccc}
\hline Score FAB & Intellectual & Mechanical & $\mathrm{P}$ \\
\hline FAB 1 & 28.3 & 28.7 & 0.28 \\
FAB 2 & 29.4 & 28.7 & 0.07 \\
FAB 3 & 28.2 & 28.6 & 0.25 \\
FAB 4 & 28.5 & 28.9 & 0.34 \\
FAB 5 & 29 & 28.9 & 0.80 \\
FAB 6 & 28.9 & 28.4 & 0.28 \\
\hline
\end{tabular}

$\mathrm{A}=$ Average $\mathrm{SD}=$ Standard Deviation .

Table 4. Gamma rhythm during the waking period and during each Frontal Assessment Battery (FAB) activity among elderlies in the intellectual and mechanical group.

\begin{tabular}{|c|c|c|c|c|c|c|}
\hline \multirow{3}{*}{ FAB } & \multicolumn{3}{|c|}{ LA } & \multicolumn{3}{|c|}{ RA } \\
\hline & INT & MEC & \multirow{2}{*}{$\mathbf{P}$} & INT & MEC & \multirow{2}{*}{$\mathbf{P}$} \\
\hline & $A \pm S D$ & $A \pm S D$ & & $\mathrm{~A} \pm \mathrm{SD}$ & $A \pm S D$ & \\
\hline GLOBAL & $28.6 \pm 0.95$ & $28.8 \pm 0.67$ & 0.62 & $28.8 \pm 1.31$ & $28.6 \pm 0.75$ & 0.85 \\
\hline FAB 1 & $28 \pm 1.82$ & $29 \pm 1.81$ & 0.18 & $28.5 \pm 1.44$ & $28.5 \pm 1.77$ & 0.94 \\
\hline FAB 2 & $29.7 \pm 2.36$ & $29.2 \pm 1.75$ & 0.55 & $29.3 \pm 2.50$ & $28.2 \pm 1.67$ & 0.20 \\
\hline FAB 3 & $28 \pm 2.14$ & $28.1 \pm 1.84$ & 0.95 & $28.1 \pm 2.12$ & $29.8 \pm 2.32$ & 0.07 \\
\hline FAB 4 & $28.3 \pm 1.65$ & $29.5 \pm 1.80$ & 0.08 & $28.7 \pm 2.21$ & $28.4 \pm 2.75$ & 0.82 \\
\hline FAB 5 & $28.9 \pm 2.27$ & $28.6 \pm 2.07$ & 0.78 & $28.7 \pm 1.71$ & $29.1 \pm 1.76$ & 0.52 \\
\hline \multirow[t]{4}{*}{ FAB 6} & $29 \pm 2.03$ & $28.5 \pm 1.24$ & 0.43 & $29.3 \pm 1.99$ & $28.1 \pm 1.24$ & 0.08 \\
\hline & & LP & & & RP & \\
\hline & INT & MEC & \multirow{2}{*}{$\mathbf{P}$} & INT & MEC & \multirow{2}{*}{$\mathbf{P}$} \\
\hline & $A \pm S D$ & $A \pm S D$ & & $A \pm S D$ & $A \pm S D$ & \\
\hline GLOBAL & $28.7 \pm 0.95$ & $28.8 \pm 0.81$ & 0.59 & $28.8 \pm 1.0$ & $28.5 \pm 1.08$ & 0.5 \\
\hline FAB 1 & $28.1 \pm 1.78$ & $28.7 \pm 1.8$ & 0.39 & $28.5 \pm 1.96$ & $28.6 \pm 1.77$ & 0.9 \\
\hline FAB 2 & $29.2 \pm 2.17$ & $28.7 \pm 1.94$ & 0.50 & $29.4 \pm 2.66$ & $28.8 \pm 1.86$ & 0.48 \\
\hline FAB 3 & $28.4 \pm 1.62$ & $28.6 \pm 2.52$ & 0.78 & $28.3 \pm 1.52$ & $28.1 \pm 2.22$ & 0.78 \\
\hline FAB 4 & $28.5 \pm 1.67$ & $29 \pm 1.90$ & 0.49 & $28.6 \pm 2.12$ & $28.7 \pm 2.29$ & 0.89 \\
\hline FAB 5 & $29.1 \pm 1.89$ & $29.4 \pm 1.92$ & 0.75 & $29.4 \pm 2.05$ & $28.6 \pm 2.18$ & 0.32 \\
\hline FAB 6 & $28.8 \pm 1.87$ & $28.9 \pm 1.82$ & 0.86 & $28.6 \pm 1.91$ & $28.4 \pm 1.32$ & 0.75 \\
\hline
\end{tabular}

LA = Left Anterior quadrant; RA = Right Anterior quadrant; LP = Left Posterior quadrant; RP = Right Posterior quadrant; INT = Intellectual group; $\mathrm{MEC}=$ Mechanical group; $\mathrm{A}=$ Average; $\mathrm{SD}=\mathrm{Standard}$ deviation.

Analysis according to activity (Table 4) showed that there was no significant difference between the groups regarding the predominance of gamma rhythm among the cerebral areas.

In the activity FAB1, there were higher activity levels in the RA and RP areas in the intellectual group, while in the mechanical group, the LA area was activated most. In the activity FAB2, the LA area AE was stimulated most in both 
groups. In the activity FAB3, the area that was most activated in the intellectual group was the LP area, whereas it was the RA area in the mechanical group. In the activity FAB4, the highest level of gamma rhythm in the intellectual group was in the RA area, while it was in the LA area in the mechanical group. In the activity FAB5, the posterior areas were more activated: RP in the intellectual group and LP in the mechanical group. In the activity FAB6, the RA area was activated most in the intellectual group, while it was the LP area in the mechanical group.

Comparison of the gamma rhythm levels between the resting period and the execution of the activities (Table 5) also did not show any significant changes. However, it can be highlighted that the gamma rhythm during the resting period was curiously elevated. Because of this, few cerebral areas showed higher values than at rest, when activities were being performed. Two findings are worth highlighting: firstly, in the activity FAB2, the level in the LA area was higher than at rest, and curiously this was seen in both groups; and secondly, in the mechanical group, the level was higher in the RA area in four of the six activities $(1,3,4$ and 5).

Table 5. Gamma rhythm during the waking period compared each Frontal Assessment Battery (FAB) activity among elderlies in the intellectual and mechanical group.

\begin{tabular}{|c|c|c|c|c|c|c|c|c|}
\hline \multirow{3}{*}{ Group } & \multirow{3}{*}{ Quadrant } & \multicolumn{7}{|c|}{ ACTIVITY } \\
\hline & & \multirow{2}{*}{$\begin{array}{c}\begin{array}{c}\text { Baseline } \\
\text { recording }\end{array} \\
\mathrm{A} \pm \mathrm{SD}\end{array}$} & \multicolumn{2}{|l|}{ FAB1 } & \multicolumn{2}{|l|}{ FAB2 } & \multicolumn{2}{|l|}{ FAB3 } \\
\hline & & & $A \pm S D$ & $\mathrm{p}$ & $A \pm S D$ & $\mathrm{p}$ & $A \pm S D$ & $\mathbf{P}$ \\
\hline \multirow{4}{*}{ Intellectual } & LA & $29.5 \pm 2.5$ & $28 \pm 1.82$ & 0.08 & $29.7 \pm 2.36$ & 0.84 & $28 \pm 2.14$ & 0.05 \\
\hline & RA & $29.6 \pm 2.07$ & $28.5 \pm 1.44$ & 0.08 & $29.3 \pm 2.50$ & 0.77 & $28.1 \pm 2.12$ & 0.01 \\
\hline & LP & $29.6 \pm 2.47$ & $28.1 \pm 1.78$ & 0.09 & $29.2 \pm 2.17$ & 0.66 & $28.4 \pm 1.62$ & 0.14 \\
\hline & $\mathrm{RP}$ & $29.4 \pm 2.35$ & $28.5 \pm 1.96$ & 0.28 & $29.4 \pm 2.66$ & 0.91 & $28.3 \pm 1.52$ & 0.19 \\
\hline \multirow{6}{*}{ Mechanical } & LA & $29 \pm 2.71$ & $29 \pm 1.81$ & 1.0 & $29.2 \pm 1.75$ & 0.85 & $28.1 \pm 1.84$ & 0.26 \\
\hline & RA & $28.2 \pm 2.64$ & $28.5 \pm 1.77$ & 0.64 & $28.2 \pm 1.67$ & 0.96 & $29.8 \pm 2.32$ & 0.08 \\
\hline & LP & $29.6 \pm 2.86$ & $28.7 \pm 1.8$ & 0.15 & $28.7 \pm 1.94$ & 0.24 & $28.6 \pm 2.52$ & 0.28 \\
\hline & $\mathrm{RP}$ & $29.1 \pm 2.72$ & $28.6 \pm 1.77$ & 0.35 & $28.8 \pm 1.86$ & 0.66 & $28.1 \pm 2.22$ & 0.08 \\
\hline & & $\begin{array}{l}\text { Baseline } \\
\text { recording }\end{array}$ & \multicolumn{2}{|l|}{ FAB4 } & \multicolumn{2}{|l|}{ FAB5 } & \multicolumn{2}{|l|}{ FAB6 } \\
\hline & & $\mathrm{A} \pm \mathrm{SD}$ & $\mathrm{A} \pm \mathrm{SD}$ & $\mathrm{p}$ & $\mathrm{A} \pm \mathrm{SD}$ & $\mathrm{p}$ & $\mathrm{A} \pm \mathrm{SD}$ & $\mathbf{P}$ \\
\hline \multirow{4}{*}{ Intellectual } & LA & $29.5 \pm 2.5$ & $28.3 \pm 1.65$ & 0.16 & $28.9 \pm 2.27$ & 0.28 & $29 \pm 2.03$ & 0.54 \\
\hline & RA & $29.6 \pm 2.07$ & $28.7 \pm 2.21$ & 0.17 & $28.7 \pm 1.71$ & 0.07 & $29.3 \pm 1.99$ & 0.57 \\
\hline & LP & $29.6 \pm 2.47$ & $28.5 \pm 1.67$ & 0.26 & $29.1 \pm 1.89$ & 0.60 & $28.8 \pm 1.87$ & 0.43 \\
\hline & $\mathrm{RP}$ & $29.4 \pm 2.35$ & $28.6 \pm 2.12$ & 0.45 & $29.4 \pm 2.05$ & 0.92 & $28.6 \pm 1.91$ & 0.31 \\
\hline \multirow{4}{*}{ Mechanical } & LA & $29 \pm 2.71$ & $29.5 \pm 1.80$ & 0.60 & $28.6 \pm 2.07$ & 0.69 & $28.5 \pm 1.24$ & 0.38 \\
\hline & RA & $28.2 \pm 2.64$ & $28.4 \pm 2.75$ & 0.86 & $29.1 \pm 1.76$ & 0.39 & $28.1 \pm 1.24$ & 0.87 \\
\hline & LP & $29.6 \pm 2.86$ & $29 \pm 1.90$ & 0.6 & $29.4 \pm 1.92$ & 0.8 & $28.9 \pm 1.82$ & 0.5 \\
\hline & RP & $29.1 \pm 2.72$ & $28.7 \pm 2.29$ & 0.67 & $28.6 \pm 2.18$ & 0.63 & $28.4 \pm 1.32$ & 0.43 \\
\hline
\end{tabular}




\section{Discussion}

The data obtained from this study through the Frontal Assessment Battery (FAB) show that elderly people who had been performing intellectual work activities presented better performance than did those who had been doing mechanical work activities. Given that the elderly people in the intellectual group had had more years of schooling, we believe that educational level may have been the main factor determining these findings. These results corroborate what was found by Paula et al. [11]. Those authors assessed healthy elderly people and observed that educational level had a significant influence on performance in the FAB tests. Another point that we noticed in our study was that the groups were more skillful in the activities that required executive capacity similar to what they had been accustomed to performing during their working lives (mechanical or intellectual).

We also observed that the elderly participants were currently less interested in intellectual activities than in mechanical activities, even if they had previously done intellectual activities. Páscoa \& Gil [12] reported that elderly people had greater difficulty in adapting to digital advances, which could be explained in terms of their entry to these technologies only in later life and in terms of the length of time that had passed since they were inside the educational system. Although digital activities are just one of the forms of intellectual activity, our view is that difficulty in mastering this while performing intellectual activities may have been one of the main reasons for these individuals' current lack of interest in intellectual activities.

In our study, the elderly subjects who had done mechanical work activities presented lower performance in the FAB than those who had done intellectual activities. This can be explained in terms of the numbers of years of schooling presented by each group. In this regard, Beato et al. [13] showed that elderly people who had had more years of formal education had significantly better performance in FAB scores.

We observed that the activity that was most difficult to do was FAB1, while the activity FAB6 was the easiest. This is corroborated by the findings of Kopp et al. [14], who evaluated 35 elderly individuals who had suffered strokes.

In relation to the lexical fluency test (FAB2), we observed that the elderly subjects who had done intellectual activities presented better performance than those who had done mechanical activities. This may have been related to the higher educational level among the individuals who had done intellectual activities. This finding is corroborated by several other studies in which it was seen that schooling level influenced performance in semantic verbal fluency tests [15] [16] [17].

In our study, the elderly participants had difficulty in doing the FAB activity involving abstract thinking. In this regard, Papalia \& Olds [18] emphasized that advancing age slows down information processing in the brain, thereby impairing performance in cognitive tests. 
Albeit without statistical significance, the elderly participants who had done mechanical work presented better performance in the motor sequence activity of the FAB of our study. This can be explained by the affirmations of Argimon [19], who suggested that the exercise done by physically active individuals may modify some physiological processes that tend to decline with advancing age.

Analysis on the FAB scores showed that these were higher among the elderly subject who had done intellectual activities than among those who had done mechanical activities. It might have been imagined that performance in the FAB items would be related to the activities performed by each group. However, this pattern was not observed, such that the individuals in the intellectual group had better performance in some items with mechanical activity, while the individuals in the mechanical group had good performance in some items with intellectual activity. Thus, there was a mixed quantification pattern.

Regarding the gamma rhythm, we observed that there was no significant difference in the potency of this rhythm among the four cerebral quadrants, between individuals who had done mechanical work activities and those who had done intellectual activities. It is difficult to interpret this result, since we did not find any similar studies in the literature.

We observed that the potency of the gamma rhythm while the item FAB3 was being performed was significantly lower than during the resting period. Given that the activity FAB3 is eminently mechanical, participation of cerebral cortex neurons was unnecessary. It was as if there was participation by subcortical areas that had not been picked up on the EEG, such that mechanical activity was performed in an automatic manner [20].

Unfortunately, information on performance in the FAB tests among elderly people without neurological conditions is scarce in the literature. Likewise, we did not find any studies in the literature that made comparisons of EEGs between elderly people who had done mechanical work and those who had done intellectual work. From our data, we can conclude that there are no differences in performance or in frontal cortical activity while activities involving executive functions measured through the FA tests are done. Thus, there is a need to undertake similar studies in order to better comprehend the adaptive processes that occur in the cerebral cortex of elderly individuals.

\section{Funding}

Arisson Euclides da Silva who held a scholarship by the CNPq e Leonardo Coelho de Mendonça Silva who held a scholarship by the Fapeal.

\section{Ethical Approval}

Approval was obtained from the ethics committee of University of Health Sciences of Alagoas. The procedures used in this study adhere to the tenets of the Declaration of Helsinki. 


\section{Informed Consent}

Informed consent was obtained from all individual participants included in the study.

\section{Conflicts of Interest}

The authors declare no conflicts of interest regarding the publication of this paper.

\section{References}

[1] Moutinho, W.T. (2019) Trabalho Braçal e Trabalho Intelectual. https://www.coladaweb.com/sociologia/trabalho-bracal-intelectual

[2] Vincenzo, S.T.S., Aquino, R.R., Ferreira, A.A.B., Maiera, R.A.L. and Pádua, S.A. (2018) Effect of Cognitive Stimulation Workshops on the Self-Esteem and Cognition of the Elderly: A Pilot Project. Dementia \& Neuropsychologia, 12, 421-426. https://doi.org/10.1590/1980-57642018dn12-040013

[3] Almondes, K.M., Matos, L.M.E. and Moreira, M.A.S. (2017) Effects of a Cognitive Training Program and Sleep Hygiene for Executive Functions and Sleep Quality in Healthy Elderly. Dementia \& Neuropsychologia, 11, 69-78. https://doi.org/10.1590/1980-57642016dn11-010011

[4] Sobral, M. and Paul, C. (2015) Reserva Cognitiva, envelhecimento e dêmencias. Revista E-Psi, 5, 113-134.

[5] Irigaray, T.Q., Schneider, R.H.G. and Gomes, I. (2011) Efeitos de um treino cognitivo na qualidade de vida e no bem-estar psicológico de idosos. Psicologia: Reflexão e Crítica, 24, 810-818. https://doi.org/10.1590/S0102-79722011000400022

[6] Lopes, R.M.F. and Argimon, I.I.L. (2016) Cognitive Training in the Elderly and Its Effect on the Executive Functions. Acta Colombiana de Psicología, 19, 159-176. https://doi.org/10.14718/ACP.2016.19.2.8.

[7] Fulgêncio, D.B., Oliveira, R.L., Fernandes, M.D.L. and Paula, J.J. (2018) Relationship between Visuospatial Episodic Memory, Processing Speed and Executive Function: Are They Stable over a Lifespan? Arquivos de Neuro-Psiquiatria, 76, 89-92. https://doi.org/10.1590/0004-282×20170186

[8] Espirito-Santo, H., Garcia, I.Q., Monteiro, B., Carolino, N. and Daniel, F. (2016) Avaliação breve do défice executivo em pessoas idosas com Acidente Vascular Cerebral: Validação da Bateria de Avaliação Frontal. Revista Portuguesa de Investigação Comportamental e Social, 2, 25-40. https://doi.org/10.7342/ismt.rpics.2016.2.2.39

[9] Cantarelli, T.L., Mendes Júnior, J.J.A. and Stevan Jr., S.L. (2016) Fundamentos da Medição do EEG: Uma introdução.

https://www.researchgate.net/publication/308400572 FUNDAMENTOS DA MED ICAO DO EEG UMA INTRODUCAO

[10] Filho, E.S.F., Lima, T.V.O., Silva, D.L.R., Costa, M.V. and Filho, E.M.T. (2016) Study of Brain Activation Using Electroencephalographic Technique for Performing Short-Term Memory Tests. World Journal of Neuroscience, 6, 37-42. https://doi.org/10.4236/wins.2016.61005

[11] Paula, J.J., Moura, S.M., Bocardi, M.B., Moraes, E.N., Malloy-Diniz, L.F. and Haase, V.G. (2013) Screening for Executive Dysfunction with the Frontal Assessment Battery: Psychometric Properties Analysis and Representative Normative Data for Brazilian Older Adults. Psicologia em Pesquisa, 7, 89-98. 
https://doi.org/10.5327/Z1982-1247201300010010

[12] Páscoa, G.M.G. and Gil, H.M.P.T. (2017) Aging and Digital Skills: A Study in Populations 50+. Revista Kairós-Gerontologia, 20, 31-56.

[13] Beato, R., Amaral-Carvalho, V., Guimarães, H.C., Tumas, V., Souza, C.P., Oliveira, G.N. and Caramelli, P. (2012) Frontal Assessment Battery in a Brazilian Sample of Healthy Controls: Normative Data. Arquivos de Neuro-Psiquiatria, 70, 278-280. https://doi.org/10.1590/S0004-282X2012005000009

[14] Kopp, B., Rösser, N., Tabeling, S., Stürenburg, H.J., De Haan, B., Karnath, H.O. and Wessel, K. (2013) Performance on the Frontal Assessment Battery is Sensitive to Frontal Lobe Damage in Stroke Patients. BMC Neurology, 13, Article No. 179. https://doi.org/10.1186/1471-2377-13-179

[15] Benito-Cuadrado, M.M., Esteba-Castillo, S., Böhm, P., Cejudo-Bolívar, J. and Peña-Casanova, J. (2002) Semantic Verbal Fluency in Animals: A Normative and Predictive Study in a Spanish Population. Journal of Clinical and Experimental Neuropsychology, 24, 1117-1122. https://doi.org/10.1076/jcen.24.8.1117.8376

[16] Mathuranath, P.S., George, A., Cherian, P.J., Alexander, A., Sarma, S.G. and Sarma, P.S. (2003) Effects of Age, Education and Gender on Verbal Fluency. Journal of Clinical and Experimental Neuropsychology, 25, 1057-1064.

https://doi.org/10.1076/jcen.25.8.1057.16736

[17] Brucki, S.M.D. and Rocha, M.S.G. (2004) Category Fluency Test: Effects of Age, Gender and Education on Total Scores, Clustering and Switching in Brazilian Portuguese-Speaking Subjects. Brazilian Journal of Medical and Biological Research, 37, 1771-1777. https://doi.org/10.1590/S0100-879X2004001200002

[18] Papalia, D.E. and Olds, S.W. (2001) Desenvolvimento Humano. 7th Edition, Artes médicas, Porto Alegre.

[19] Argimon, I.I.L. (2006) Aspectos cognitivos em idosos. Avaliação Psicológica, 5, 243-245.

[20] Alvarez, J.A. and Emory, E. (2006) Executive Function and the Frontal Lobes: A Meta-Analytic Review. Neuropsychology Review, 16, 17-42.

https://doi.org/10.1007/s11065-006-9002-x 